\title{
Research on Spatiotemporal Variation of Soil Temperature in China from 1948 to 2018
}

\author{
Mengyuan Zang1, Mengqing Geng'2, Feng Zhang2, Qiulan $\mathrm{Wu}^{2}$, Yong Liang2 \\ ${ }^{1}$ School of Economics and Management, Shandong Agricultural University, Tai'an, China \\ ${ }^{2}$ College of Information Science and Engineering, Shandong Agricultural University, Tai'an, China \\ Email: zhangfeng@sdau.edu.cn
}

How to cite this paper: Zang, M.Y., Geng, M.Q., Zhang, F., Wu, Q.L. and Liang, Y. (2020) Research on Spatiotemporal Variation of Soil Temperature in China from 1948 to 2018. Journal of Environmental Protection, 11, 570-584.

https://doi.org/10.4236/jep.2020.118034

Received: June 21, 2020

Accepted: July 28, 2020

Published: July 31, 2020

Copyright () 2020 by author(s) and Scientific Research Publishing Inc. This work is licensed under the Creative Commons Attribution International License (CC BY 4.0).

http://creativecommons.org/licenses/by/4.0/

\section{(c) (i) Open Access}

\begin{abstract}
The change of soil temperature can affect the regional climate, so it is of great significance to research the spatial and temporal evolution characteristics of regional soil temperature over a long period of time for the research of the land-air interaction, climate change and ecological agricultural construction. We use the v2.0 and v2.1 data set combined with GLDAS and Noah models to analyze the spatiotemporal variation of temperature in soil layers of $0-200$ $\mathrm{cm}$ in China during the period of 71 years from 1948 to 2018. Firstly, the Mann-Kendall test method is used to research the variation trend of soil temperature over the past 71 years in China and the spatial variation of these trends. Secondly, by calculating the spatiotemporal coefficient of variation (CV) of soil temperature, the spatial-temporal fluctuation of soil temperature in China is further studied and analyzed. Finally, the Hurst index is used to analyze the possible future trend of soil temperature in China. Based on these methods, we have drawn the following conclusions: 1) The soil temperature in most areas of northern China had an increasing trend, especially in the northeast China. The soil temperature in most of the south China had a decreasing trend. The temperature trends of the four soil layers had little difference, and it remained stable on the whole. 2) The regional difference of soil temperature in China remained stable before 1999, and decreased suddenly in 2000. After 2008, the regional difference increased. Compared with the previous period, the temperature in some areas increased or decreased abnormally. 3) The soil temperature in eastern, southeast China and Xinjiang had a relatively significant variation in the 71 years. From $0-10 \mathrm{~cm}$ soil surface to $100-200 \mathrm{~cm}$ soil bottom, the spatial difference of temperature gradually decreased, which was due to the fact that the soil temperature was more affected by the surface atmospheric temperature. 4) The soil temperature in the north and northwest of China will continue to grow, and in the southern-most
\end{abstract}


will continue to decrease. The soil temperature in the north of central China will become a decreasing trend, while the temperature in the south of central China will become an increasing trend.

\section{Keywords}

China, Soil Temperature, Spatiotemporal Variation, GLDAS, Mann-Kendall, Hurst Index

\section{Introduction}

Soil temperature, an important physical property of soil, can affect the energy and water exchange between land and atmosphere by changing the surface thermal state, and then affect the regional climate [1]. Soil temperature has different effects on the bio-chemical process of soil materials and the quality of soil resources [2], and can be used as a judgment factor to predict the future land-atmosphere material and energy exchange relationship [3]. Its regional differentiation and seasonal variation directly affect the growth, development, reproduction and distribution of soil organisms, which are closely related to agricultural production and ecological environment [4] and provide important scientific basis for agricultural regional planning and ecological agriculture construction in China.

There are some researchers who have studied the spatiotemporal evolution of soil temperature in some regions in China and demonstrated the close relationship between soil temperature and climate environment. Yang Nan et al. [5] analyzed the variation characteristics of soil temperature on the Qinghai-Tibet plateau from 2000 to 2016 by using methods such as linear tendency estimation and empirical orthogonal function decomposition, and they drew a conclusion that soil temperature on the Qinghai-Tibet plateau is inversely correlated with both altitude and latitude and increased year by year. Wu Haomin et al. [6] detected the trend and sudden variation of soil temperature in Lishui city from the two different time dimensions of year and season, and concluded that soil temperature was highly correlated with air temperature and precipitation. Yang Xia and Zhao Yizhou et al. [7] used the observation data of the 9-layer soil temperature at the automatic station in Aksu area, and consequently found that the diurnal variation of the soil temperature apparatus at different levels was also significantly different and solar radiation had a corresponding effect on the change and distribution of soil temperature. Meng Xianyong et al. [8] confirmed that CLM3.5 model under the force of CLDAS driving field could accurately reflect the temporal variation law of soil temperature in three soil layers $(5 \mathrm{~cm}, 20 \mathrm{~cm}$ and $80 \mathrm{~cm}$ ) in Xinjiang, China. Yang Nan, Wu Haomin and Yang Xia et al. [9] all studied the spatial-temporal variation of soil temperature on a small scale, with a small-time span and few studies on the depth variation characteristics of 
soil temperature.

Researchers have also done some researches on soil temperature of the whole China. Using the monthly average $0.8 \mathrm{~m}$ layer ground temperature data of 532 stations in China from 1954 to 2001, Lu Xiaobo et al. [10] analyzed the variation characteristics of ground temperature in the different regions in China. They confirmed that in this period, the interdecadal variation of annual mean ground temperature in China could be roughly divided into three stages: the declining stage, the relative cold stage and the rising stage; and in the meantime, the regional variation characteristics of ground temperature are significant. According to the ground climatic data from 1971 to 2000 of annual and monthly average soil temperature, air temperature and precipitation, Zhang Huizhi et al. [11] analyzed the seasonal variation of soil temperature in China as well as the characteristics of the regional differentiation, and analyzed the influence of temperature and precipitation on soil temperature. They confirmed that in China the seasonal variation of soil temperature was very obvious, and the seasonal variation was significant difference among different regions. Based on IBIS model, Zhu Qiu'an [12] simulated the annual and monthly average soil temperature of the upper soil layer of $1 \mathrm{~m}$ in China from 1955 to 2006, and they used the Mann-Kendall method to analyze the trend of annual and monthly average soil temperature. They drew the conclusion that for the annual average soil temperature, the north had significant increasing trend, but the south had weak increasing trend.

Although these studies have explored many spatiotemporal characteristics of soil temperature in China, there are still some problems to be further explored: 1) although the trend of soil temperature in China in the past long time series has been studied, the spatial variation of this trend needs further exploration; 2) the time-variation of annual spatial variation of soil temperature in China, and spatial-variation of soil temperature in a long time series need to be explored; 3) what is the possible future trend of soil temperature in China?

In view of the above problems that need further exploration, this paper extends the research time to 71 years from 1948 to 2018 to explore the spatial-temporal variation of soil temperature trend, the spatial-temporal fluctuation characteristics and the future trends of soil temperature, so as to complement existing studies. The contributions of this paper include the following three aspects: 1) the Mann-Kendall test is used to research the variation trend of soil temperature over the past 71 years in China, and the spatial variation of these trends are analyzed; 2) the annual spatial variation coefficient of soil temperature in the research area for 71 years and the $\mathrm{CV}$ of soil temperature in time series are calculated to analyze the spatial and temporal fluctuations of soil temperature in different depths; 3 ) the Hurst index is used to predict the possible future trend of soil temperature in China.

The structure of the rest of this paper is as follows: the second part explains the data sources and research methods. The third part analyzes the data processing results. The fourth part carries on the summary analysis to draw the re- 
search conclusion.

\section{Data and Method}

\subsection{Data}

The data sets used in this paper are from the European space agency's (ESA) global land data assimilation system (GLDAS). GLDAS is a data assimilation system based on satellites, surface models and ground observations [13]. The meteorology-driven data used in GLDAS are derived from multi-source observations, reanalyzed data and atmospheric assimilation products, which had high applicability in regional studies. Jiang et al. [14] and Wang Wen et al. [15] confirmed the applicability of GLDAS in China, and the data had been widely used in the research of soil temperature in China [5] [9] [16] [17] [18]. This paper uses the v2.0 and v2.1 data set combined with GLDAS and Noah models [18] [20] [21]. The soil temperature in these data sets includes four layers: $0-10 \mathrm{~cm}, 10$ $40 \mathrm{~cm}, 40-100 \mathrm{~cm}$, and $100-200 \mathrm{~cm}$. The time series are 1948-1999 and 2000-2018. The spatial resolution is $0.25^{\circ} \times 0.25^{\circ}$, and the temporal resolution is monthly. Using these data, we evaluate the temporal and spatial variation characteristics of the temperature in the $0-200 \mathrm{~cm}$ soil layer in China.

The research area of this paper is mainland China and two islands in southern China. The maps in this paper do not show other smaller islands in the South China Sea.

\subsection{Mann-Kendall Trend Test}

The Mann-Kendall test, proposed by H. B. Mann and M. G. Kendall, is originally used for climate diagnosis and prediction, and is a distribution-free test method, which does not require samples to conform to a certain distribution, nor to be disturbed by a few outliers. And it is widely used in the significance test of time series trend [22]. It has been used in the research of soil temperature [8] [23] and proved its applicability.

For time series variables $\left(x_{1}, x_{2}, \cdots, x_{t}\right), t$ is the length of the time series, and $\mathrm{M}-\mathrm{K}$ method defines the statistics.

$$
S=\sum_{k=1}^{n-1} \sum_{j=k+1}^{n} \operatorname{sgn}\left(x_{j}-x_{k}\right)
$$

where, " $n$ " is the total sample, $\mathrm{j}$ and $k=1,2, \cdots, n \cdot x_{j}$ and $x_{k}$ are the sample values at time $j$ and $k$ respectively. Sign() is a symbolic function, and the rules are as follows:

$$
\operatorname{sgn}\left(x_{j}-x_{k}\right)= \begin{cases}1, & x_{j}-x_{k}>0 \\ 0, & x_{j}-x_{k}=0 \\ -1, & x_{j}-x_{k}<0\end{cases}
$$

$S$ is normal distribution, the mean value is 0 , and the variance $\operatorname{var}(S)=n(n-1)(2 n+5) / 18$. When $n>10$, the normal distribution statistics 
are calculated as follows:

$$
Z_{c}= \begin{cases}\frac{S-1}{\sqrt{\operatorname{var}(S)}}, & S>0 \\ 0, & S=0 \\ \frac{S+1}{\sqrt{\operatorname{var}(S)}}, & S<0\end{cases}
$$

If $Z>0$, it indicates that the soil temperature has an increasing trend in this time period; otherwise, it is a decreasing trend, and the larger the absolute value is, the more obvious the trend will be. When $Z$ value is greater than or equal to $1.28,1.64$ and 2.32 , the confidence level is $90 \%, 95 \%$ and $99 \%$ respectively.

\subsection{Coefficient of Variation}

Coefficient of Variation (CV) is used to measure the degree of Variation between samples with different units or large mean differences [24], and to reflect the absolute value of the degree of dispersion of data. Coefficient of variation is an objective statistic that can well avoid the interference of subjective factors [25] When comparing the dispersion degree of two sets of data, coefficient of variation can eliminate the influence caused by too big difference in measurement scales or different data dimensions [26]. We can use the coefficient of variation to measure the fluctuated of a data series.

The calculation method of variation coefficient is as follows:

$$
C_{v}=\frac{\sigma}{\bar{\mu}}
$$

where, $C_{v}$ is the coefficient of variation, $\sigma$ is the standard deviation of the soil temperature data of the time series, and $\bar{\mu}$ is the mean value of the soil temperature data of the time series.

\subsection{Hurst Index}

The research on Hurst index began with the British hydrologist H. E. Hurst, who found that the long-term storage capacity of reservoirs could be better described by the partial random walk (fractal Brownian motion), and on this basis proposed the method of re-scale range $(R / S)$ analysis to establish the Hurst index $(H)$. Moreover, Hurst index is used as an indicator to determine whether time series data follow a random walk or a biased random walk as well. Hurst index is used in many related research works [27] [28] [29], and it has been proved that it is suitable for studying temperature.

The soil temperature time series is defined as the $\xi_{(t)}$, where $t=1,2,3, \cdots, n$, for any positive integer $\tau \geq 1$, or more, the time sequence of the mean sequence is:

$$
\overline{\xi_{(t)}}=\frac{1}{\tau} \sum_{t=1}^{\tau} \xi_{(t)},(\tau=1,2,3, \cdots)
$$

Cumulative differential sequence: 


$$
X_{(t, \tau)}=\sum_{t=1}^{\tau}\left(\xi_{(t)}-\overline{\xi_{(\tau)}}\right)
$$

The range sequence is:

$$
R_{(\tau)}=\max X_{(t, \tau)}-\min X_{(t, \tau)},(1 \leq t \leq \tau)
$$

The standard deviation sequence is:

$$
S_{(\tau)}=\left[\frac{1}{\tau} \sum_{t=1}^{\tau}\left(-\left(\xi_{(t)}-\overline{\xi_{(\tau)}}\right)\right)^{2}\right]^{\frac{1}{2}}
$$

The Hurst index is calculated as:

$$
\frac{R_{\tau}}{S_{\tau}}=(c \tau)^{H}
$$

where, $H$ represents the Hurst exponent and $c$ is the proportional parameter. To take logarithm on both sides, in double logarithmic coordinate system $\left(\ln \left(R_{\tau} / S_{\tau}\right)\right.$, $\ln \tau$ ) with least square fitting, draw a straight-line slope is the Hurst index. The value range of Hurst index is $(0,1)$, which can be divided into three cases:

1) when $0<H<0.5$, the sequence has anti-persistence, that is, the future trend is contrary to the past trend, and the closer $H$ is to 0 , the stronger the anti-persistence;

2) when $H=0.5$, it is a random sequence, that is, the trend of future change has nothing to do with the trend of the past;

3) when $0.5<H<1$, the future trend is consistent with the past trend, and the closer $H$ is to 1 , the stronger the persistence.

\section{Result}

\subsection{Analysis of Soil Temperature Variation Trend}

In order to explore the trend of the average soil temperature in each layer in China from 1948 to 2018, we extract and count the temperature data of $0-200$ $\mathrm{cm}$ soil layer from GLDAS data, calculate the Z-value of each pixel using the Mann-Kendall test method, and finally draw the distribution map of the temperature trend in each layer according to the Z-value, as shown in Figure 1.

According to the theory of Mann-Kendall test, as shown in Figure 1, the four layers of soil in the spatial distribution of $\mathrm{Z}$-value in the 71 years is roughly same, which shows that with the increase of soil depth, the spatial distributions of the temperature trends of 4 soil layers in 1948-2018 were very similar. The South and north of China have very different trends. The soil temperature in most parts of northern China in the 71 years had an increasing trend, especially in northeast China, the northern and central Inner Mongolia, the southwestern Tarim basin, the western Tianshan mountains, the northern Junggar basin, the Tibetan plateau, and some parts of southern China such as the northern Sichuan basin, the north of the middle-lower Yangtze plain, and the island of Taiwan. The increasing trend of soil temperature is most obvious in the island of Taiwan. As is shown in Figure 1, the $\mathrm{Z}$-value of the areas just mentioned is greater than 

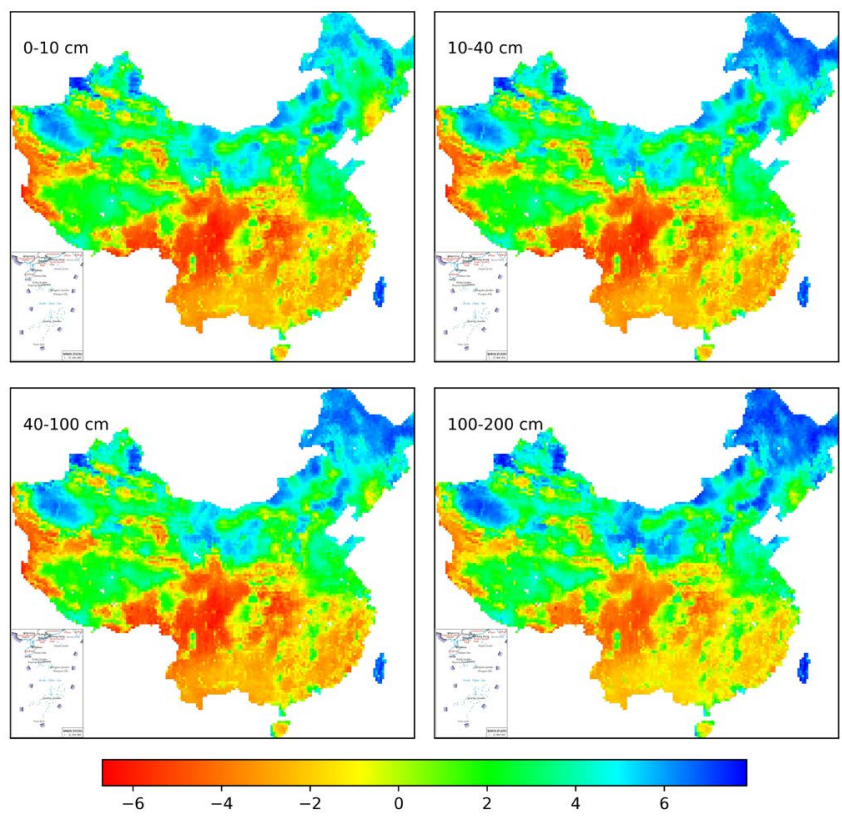

Figure 1. Spatial distribution of Mann-Kendall Z-values of soil average temperature in different layers in China from 1948 to 2018. If $Z>0$, it indicates that the soil temperature has an increasing trend in this time period; otherwise, it is a decreasing trend, and the larger the absolute value is, the more obvious the trend will be. The figure is produced using the map with review number GS (2019) 1823 by Ministry of natural resources of China.

0 , which means that the $0-200 \mathrm{~cm}$ layer soil temperature in these areas over the past 71 years was on the increase. But other areas in most parts of southern China had the decreasing trend, such as the southeast Qinghai-Tibet plateau, the western-southern Tarim basin, the Yunnan-Guizhou plateau, the central-southern loess plateau, the most part of middle-lower Yangtze plain, the east of Wuyi mountains, and Hainan island. Particularly in the east-southeast Qinghai-Tibet plateau, the Tianshan mountains, and some areas of the Gaidam basin, the $\mathrm{Z}$-value is less than 0 , indicating that these areas had gradually cooled down in the past 71 years.

Table 1 shows the proportion of pixel number in each distribution interval of $\mathrm{Z}$-value. According to statistics, there are about 68,600 pixels in the research area, among which, in the $0-10 \mathrm{~cm}$ soil layer, 13,564 pixels with Z-value are greater than 0 , accounting for about $19.77 \%$, and $80.23 \%$ of the pixels with $\mathrm{Z}$-value are less than 0 . In the $10-40 \mathrm{~cm}$ soil layer, 11320 pixels with $\mathrm{Z}$-value are greater than 0 , accounting for about $16.50 \%$, and $83.50 \%$ of the pixels with $Z$-value are less than 0 . In the $40-100 \mathrm{~cm}$ soil layer, there are 10380 pixels with Z-value greater than 0 , accounting for about $15.13 \%$. The number of pixels with $Z$-value less than 0 account for $84.87 \%$. In the $100-200 \mathrm{~cm}$ soil layer, 8864 pixels with Z-value are greater than 0 , accounting for about $12.92 \%$, and $87.08 \%$ of the pixels with $Z$-value are less than 0 . From these statistical data, the proportions of the pixel numbers in each $Z$-value distribution interval have little difference in four layers. On the whole the Z-values less than 0 account for about $85 \%$, and 
Table 1. Statistics of Z-value distribution interval of each soil layer.

\begin{tabular}{ccccc}
\hline Z value range & $0-10 \mathrm{~cm}$ & $10-40 \mathrm{~cm}$ & $40-100 \mathrm{~cm}$ & $100-200 \mathrm{~cm}$ \\
\hline$Z \leq-2.32$ & $13.0 \%$ & $16.7 \%$ & $18.5 \%$ & $21.1 \%$ \\
$-2.32<Z \leq-1.64$ & $3.6 \%$ & $3.7 \%$ & $3.7 \%$ & $3.6 \%$ \\
$-1.64<Z \leq-1.28$ & $1.9 \%$ & $2.1 \%$ & $1.8 \%$ & $1.7 \%$ \\
$-1.28<Z \leq 0$ & $61.7 \%$ & $61.0 \%$ & $60.8 \%$ & $60.7 \%$ \\
$0<Z \leq 1.28$ & $5.1 \%$ & $3.6 \%$ & $3.7 \%$ & $3.3 \%$ \\
$1.28<Z \leq 1.64$ & $1.3 \%$ & $0.9 \%$ & $0.9 \%$ & $0.8 \%$ \\
$1.64<Z \leq 2.32$ & $2.8 \%$ & $1.7 \%$ & $1.7 \%$ & $1.2 \%$ \\
$Z>2.32$ & $10.6 \%$ & $8.9 \%$ & $8.9 \%$ & $7.6 \%$ \\
\hline
\end{tabular}

the $\mathrm{Z}$-values greater than 0 account for about $15 \%$. So about $85 \%$ of the research area had a decreasing trend during this period, while about $15 \%$ of the area was on the increase.

Meanwhile, the statistics in Table 1 show that most pixels with growth trends are in a relatively high increasing trend. About $9 \%$ of the pixels have the $\mathrm{Z}$-value greater than 2.32, indicating that the areas covered by these pixels have $99 \%$ chance of increasing trend. However, most of the pixels with a decreasing trend were in a lower decreasing trend. About $61 \%$ of the pixels had Z-values less than 0 and greater -1.28 , indicating that the areas covered by these pixels had less than $90 \%$ chance of decreasing trend. In general, soil temperature in most areas of China was on a decreasing trend. It can be seen from the combination of Figure 1 and Table 1 that the soil temperature between 0 and $200 \mathrm{~cm}$ in most parts of China had a general cooling trend since 1948, and the temperature had little difference between every soil layer.

\subsection{Time-Variation of Annual Spatial Variation of Soil Temperature}

We calculated the annual spatial CV of the temperature of the four soil layers in China during the 71-year period from 1948-2018, and plot the line graph of these CV value, as shown in Figure 2. We can see the spatial variation fluctuation of each soil layer from 1948 to 2018.

In Figure 2, the blue, orange, green, red fold lines respectively represent the $\mathrm{CV}$ curve of soil temperature of $0-10 \mathrm{~cm}, 10-40 \mathrm{~cm}, 40-100 \mathrm{~cm}, 100-200 \mathrm{~cm}$. As shown in Figure 2, from top to bottom, the CV values decrease gradually with the increase of soil depth, that is, the spatial variation of soil temperature in the research area became smaller with soil becoming deeper, indicating that the temperature in the deeper soil was more well-distributed in the past 71 years, and the spatial variation of soil temperature was greatly affected by surface factors. In addition, the fluctuation of these four-fold lines is roughly similar, indicating that the fluctuation trends of the temperature spatial CV of these four soil layers were basically similar from 1948 to 2018. 


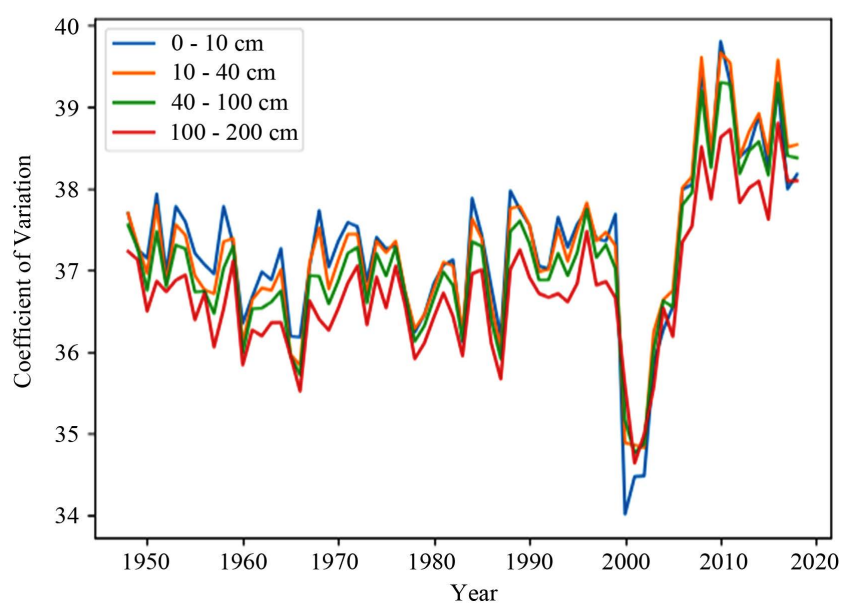

Figure 2. Time variation of spatial distribution of soil temperature CV.

The fluctuation of spatial CV of soil temperature in each layer can be divided into two stages. In the first stage, from 1948 to 1999, the spatial CV of each layer fluctuated in a small range from 35.5 to 38 . Moreover, the temperature CV value of the four soil layers fluctuated slightly, indicating that the soil temperature in China was relatively uniform. The second stage is that the spatial CV of soil temperature in each layer fluctuates in a wide range in 2000 and later. In 2000, the spatial CV of the soil layer in the research area plummeted to a very low point which was close to 34 . There was a small increase over the next two or three years, but the overall CV value remained below 35 . Roughly from 2003, the spatial CV returned to its previous level, but in 2008, the spatial CV had ballooned to a higher level than before. From 2008 to 2018, the spatial CV was again in a state of small fluctuation between the highest value of 40 and the lowest value of 38. The CV values were higher than before, and the fluctuation range was also greater than before. This shows that in China the spatial variation of 0 $200 \mathrm{~cm}$ layer soil temperature reached the lowest in 2000 indicating that the soil temperature in the research area was well-distributed in this year. It became more nonuniform after 2000, and before 2008 the regional variation was still less than the first stage. But after 2008 the variation increased markedly, and became greater than the first stage which indicates that compared with before there was abnormal temperature rising or falling in some areas, and confirms that soil temperature in China became more nonuniform after 2008.

\subsection{Spatial-Variation of Soil Temperature in Time Series}

By calculating the $\mathrm{CV}$ of soil temperature of each pixel in time series of the four soil layers in 71 years from 1948 to 2018, the spatial distribution map of the time series CV is obtained, as shown in Figure 3.

As is shown in Figure 3, the CV values of soil temperature of four layers in time series from 1948 to 2018 had performances with decreasing firstly and then gradually increasing trend from northwest to southeast, indicating that the 0 $200 \mathrm{~cm}$ soil temperature in southeast China had fluctuated greatly in 71 years. 

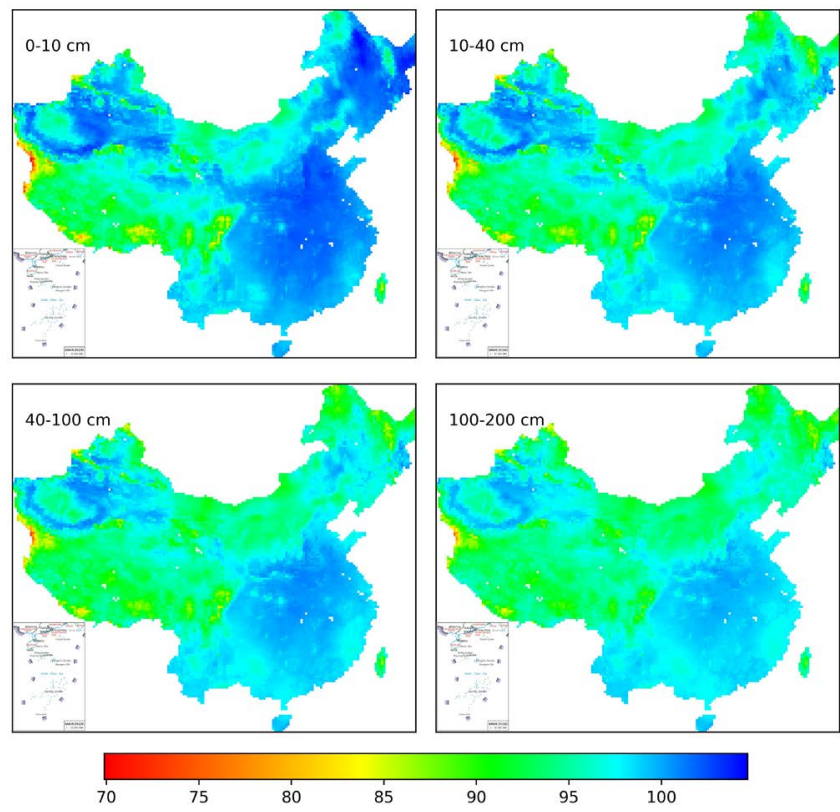

Figure 3. Spatial variation of soil temperature $\mathrm{CV}$ in time series. The colorbar values means the CV values, the greater the value, the greater the variation of soil temperature. The figure is produced using the map with review number GS (2019) 1823 by Ministry of natural resources of China.

Moreover, the fluctuation in the southeast and northwest was greater than that of the southwest and northeast. The greater the fluctuation was, the more unstable the soil temperature in these areas was, spatially the $0-10 \mathrm{~cm}$ soil layer. In the $0-10 \mathrm{~cm}$ soil layer, the CV values of soil temperature in the surrounding areas of the Tarim basin, part of the Tianshan and Junggar basins, the Yunnan-Guizhou plateau, the north China plain, the middle-lower Yangtze plain, the Wuyi mountains and its surrounding areas, and Hainan island were larger than 95, and were higher than other areas. This phenomenon indicates that the soil temperature in these areas fluctuated greatly during the 71-years. And especially in most areas of Xinjiang, the north China plain and the middle and lower Yangtze plain, the soil temperature variation was the most unstable in the 0 - 200 $\mathrm{cm}$ soil layer. While other areas had smaller CV values, such as the Qinghai-Tibet plateau, the Inner Mongolia plateau, the Loess plateau, the Northeast plain, the Greater Hinggan mountains, and a small part of the western Qinghai-Tibet plateau, which indicates in these areas the soil temperature fluctuated larger in the 71 years from 1948 to 2018.

With the soil deeper, the CV of soil temperature in time series fluctuated less, especially in northeast China, the north and south Tianshan mountains, and central Inner Mongolia plateau. More specifically, in northeast China, the CV value was close to 110 in the $0-10 \mathrm{~cm}$ soil layer, while it decreased close to 90 in the $100-200 \mathrm{~cm}$ soil layer, which indicates that in these areas, with the increase of soil depth, the CV of soil temperature in time series became smaller and the variation of soil temperature became more uniform. In other areas, the $\mathrm{CV}$ of soil temperature in time series did not change significantly with the increase of 
soil depth, indicating that the variation of soil temperature in time series in these areas was not significantly affected by depth, and the soil temperature in these regions was relatively uniform.

\subsection{Analysis of Future Trend of Soil Temperature}

According to the soil temperature from 1948 to 2018, the Hurst index of each pixel was calculated and the Hurst index distribution map was drawn, as shown in Figure 4.

As can be seen from Figure 4:

1) The Hurst index value distribution map of the four layers of soil $0-200 \mathrm{~cm}$ is mostly similar, and the Hurst index values of the most pixels in the research area are less than 0.5 , which reveals that the trend of soil temperature in most parts of China in the future is contrary to the trend from 1948 to 2018, especially in the eastern part of the Northeast plain, the north China plain, the central and eastern Inner Mongolia plateau, the Loess plateau, the Yunnan-Guizhou plateau, the Himalayas, and the middle-lower Yangtze plain. In these areas, the anti-persistence is particularly stronger in the middle-lower Yangtze plain, and the northern border between the Sichuan basin and the Qinghai-Tibet plateau. To be more specific, the trend in most parts of central China will reverse the trend from 1948 to 2018, that is to say, the soil temperature in northern central China increased before but would decrease in the future; while the temperature in southern central China decreased before but will increase in the future. And in the central and north areas of the northeast China plain, the north Greater
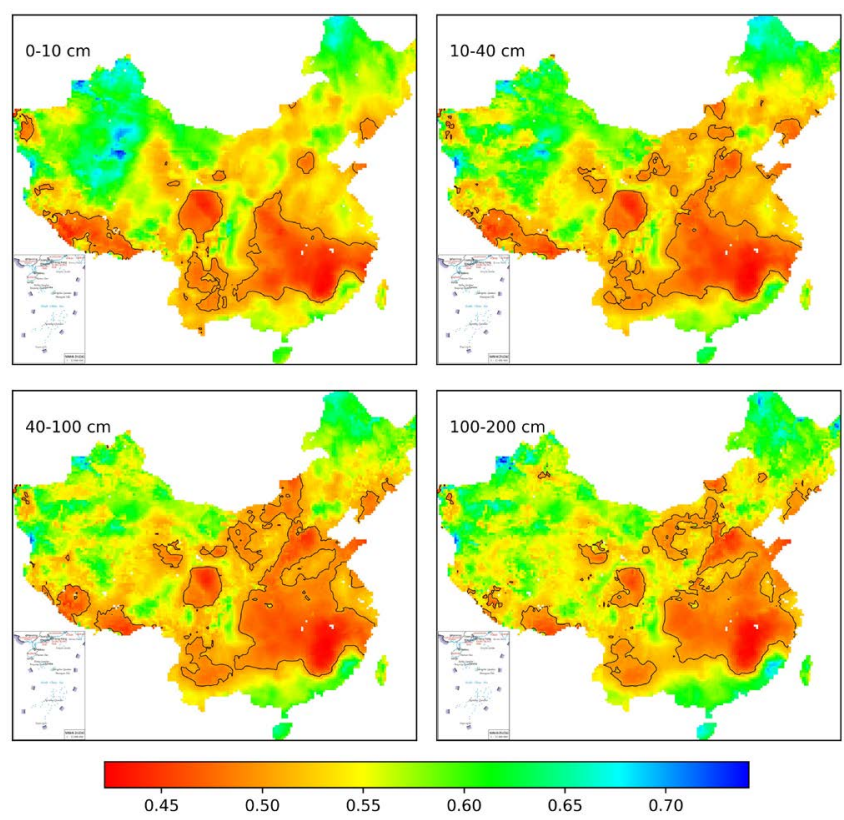

Figure 4. Distribution of Hurst values $H$ over the years from 1948 to 2018 . The black curve in the figure is the dividing line of 0.50 . When $0<H<0.5$, the sequence has anti-persistence. When $H=0.5$, it is a random sequence. When $0.5<H<1$, the future trend is consistent with the past trend. The figure is produced using the map with review number GS (2019) 1823 by Ministry of natural resources of China. 
Hinggan mountains, the Junggar basin, Tianshan, Tarim basin, Jiangnan hilly, the south Hainan island and Tanwan island, the Hurst index is greater than 0.5, illustrating that the soil temperature in these areas in the future will continue to maintain the existing trend, namely the soil temperature in the northeast and northwest China will continue to increase, whereas in southern China it will continue to decrease. Moreover, in the $0-40 \mathrm{~cm}$ soil layer, Hurst index value exceeds 0.7 in Xinjiang, proving that the future change direction of soil temperature in this part is more consistent with the past.

2) With the increase of soil depth in areas of China, the future trend of soil temperature varies. In some areas, such as northwestern China and the north China plain, the temperature trend at the bottom of the soil is more obvious than at the surface. However, in other areas, such as the eastern Qinghai-Tibet plateau and the coastal areas in southern China, the future sustainability is stronger with soil deeper.

\section{Conclusions and Discussions}

Through the above analysis, the following conclusions can be drawn:

1) On the whole, the south and north of China have very different trends in the past 71 years. The soil temperature in most areas of northern China had an increasing trend, especially in the northeast China, the central and northern Inner Mongolia, the southwest of Tarim Basin, the Western Tianshan Mountains, the northern Junggar Basin and Taiwan Island. The soil temperature in most of the south China had a decreasing trend, especially in the east and west of Tibet Plateau, and Yunnan-Guizhou Plateau. The temperature trends of the four soil layers had little difference, and it remained stable on the whole in the past 71 years.

2) From the perspective of time-variation of annual spatial variation of soil temperature, the spatial CV of soil layers in the research area changed basically the same with time. From 1948 to 1999, the spatial CV of each layer was in a state of fluctuation with a small range. In 2000, the spatial CV suddenly decreased to a very low point, and then in 2003, the spatial variation coefficient returned to the previous level, but after 2008, the spatial CV began to increase to a higher level. This shows that the regional difference of soil temperature in China remained stable before 1999, and decreased suddenly in 2000. After 2008, the regional difference increased. Compared with the previous period, the temperature in some areas increased or decreased abnormally.

3) From the perspective of spatial-variation of soil temperature in time series, the spatial variation of soil temperature in the 71 years in the research area was relatively obvious, and the spatial variation of each soil layer was basically decreasing from the southeast coast to the northwest, and then increasing to Xinjiang. This shows that the soil temperature in eastern, southeast China and Xinjiang had a relatively significant variation in the 71 years. The spatial variation of each soil layer was also inconsistent. From $0-10 \mathrm{~cm}$ soil surface to $100-200 \mathrm{~cm}$ 
soil bottom, the spatial difference of temperature gradually decreased, which was due to the fact that the soil temperature was more affected by the surface atmospheric temperature.

4) From the perspective of future trend prediction of soil temperature, the Hurst value in the north, northwest and southernmost areas of China is greater than 0.5 , indicating that the trend of soil temperature in these areas will continue to the existing trend, that is, the soil temperature in the north and northwest of China will continue to grow, and in the southernmost will continue to decrease. The trend of most areas in the central China will be the opposite of the trend from 1948 to 2018. That is to say, the soil temperature in the north of central China originally increased, and it will become a decreasing trend in the future, while the temperature in the south of central China originally decreased, and it will become an increasing trend in the future. The difference of each soil layers is not big, but the opposite trend of the soil surface layer is more obvious than the bottom of $100-200 \mathrm{~cm}$.

On the basis of the conclusions, we have a clearer understanding of the spatial variation of the soil temperature and find some previously unknown characteristics. Compared with previous researches, our research is unique in that:

1) We not only studied the trend of soil temperature in China in the past long time series has been studied, we also studied the spatial variation of this trend.

2) We studied the time-variation of annual spatial variation of soil temperature in China, and spatial-variation of soil temperature in a long time series.

3) We explored the possible future trend of soil temperature in China.

Although the applicability of the research data and related research methods in China or its related fields has been proved, the accuracy of the conclusions still needs to be further verified. In addition, it is necessary to continue to analyze not only the spatiotemporal variation of other factors related to soil temperature but also the relationship between these factors to explore the driving factors of these spatiotemporal variations. These are all the directions of our next work.

\section{Conflicts of Interest}

The authors declare no conflicts of interest regarding the publication of this paper.

\section{References}

[1] Yu, J.H., Rong, Y.S. and Ren, J. (2005) The Influence of Surface Temperature of Qinghai Tibet Plateau on Precipitation Change in Flood Season in North China. Meteorological Science, No. 6, 579-586.

[2] Zhang, Z.H., Shi, X.Z. and Yu, D.S. (2009) Seasonal Land Regional Variations of Soil Temperature in China. Acta Pedologica Sinica, 46, 227-234.

[3] Cheng, Q.P., Wang, P. and Xu, Q. (2017) Temporal and Spatial Variation Characteristics of Surface Temperature in Yunnan during 1960-2013. Research of Soil and Water Conservation, 24, 111-121+397. 
[4] Yang, X., Zhao, Y.Z., Luo, J. and Zhao, X. (2011) Characteristics of Soil Temperature Variations in Akesu. Journal of Arid Land Resources and Environment, 12, 97-101.

[5] Li, X., Gao, Y.H., Wang, W.Z., et al. (2014) Climate Change and Applicability of GLDAS in the Headwaterof the Yellow River Basin. Advances in Earth Science, 29, 531-540.

[6] Lu, X.B., Xu, H.M., Sun, C.H. and He, J.H. (2006) Variation Characteristics of Earth Temperature near 50 a in China. Journal of Nanjing Meteorological University, 29, 706-712.

[7] Zhang, H.Z., Shi, X.Z., Yu, D.S., et al. (2009) Research on Seasonal Variation and Regional Differentiation of Soil Temperature in China. Acta Pedologica Sinica, 46, 227-234.

[8] Zhu, Q., Jiang, H., Liu, J.X., et al. (2010) Soil Temperature Simulation and Spatio-Temporal Evolution Analysis in China from 1955 to 2006 Based on IBIS Model. Geographic Sciences, 30, 355-362.

[9] Yang, N. and Fan, G.Z. (2019) Analysis of Soil Temperature Variation over the Qinghai-Xizang Plateau from 2000 to 2016. Journal of Southwest University (Natural Science Edition), 41, 40-51.

[10] Lu, X.B., Xu, H.M., Sun, C.H., et al. (2006) Characteristics of Soil Temperature Variations in China in Recent 50 Years. Journal of Nanjing Institute of Meteorology, No. 5, 706-712.

[11] Wang, X.T., Guo, W.D., Zhong, Z., et al. (2009) Long Term Trends of Soil Moisture and Temperature Change in East China in Relationship with Climate Background. Advances in Earth Science, 24, 181-191.

[12] Zhu, Q., Jiang, H., Liu, J.X., et al. (2010) Simulation and Trend Analysis of Soil Temperature in China from 1955 to 2006 Using IBIS Model. Scientia Geographica Sinica, 30, 355-362.

[13] Rodell, M., Houser, P.R., Jambor, U., Gottschalck, J., Mitchell, K., Meng, C.-J., Arsenault, K., Cosgrove, B., Radakovich, J., Bosilovich, M., Entin, J.K., Walker, J.P., Lohmann, D. and Toll, D. (2004) The Global Land DataAssimilation System. Bulletin of the American Meteorological Society, 85, 381-394. https://doi.org/10.1175/BAMS-85-3-381

[14] Jiang, Y.Y., Wang, W. and Zhou, Z.-H. (2017) Evaluation of MODIS MOD16 Evapotranspiration Product in Chinese River Basins. Journal of Natural Resources, 32, 517-528.

[15] Wang, W., Wang, X.J. and Wang, P. (2014) Assessing the Applicability of GLDAS Monthly Precipitation Data in China. Advances in Water Science, 25, 769-778.

[16] Yang, K. and Zhang, J.Y. (2018) Evaluation of Reanalysis Datasets against Observational Soil Temperature Data over China. Climate Dynamics, 50, 317-337. https://doi.org/10.1007/s00382-017-3610-4

[17] Wang, L., Li, X.P., Chen, Y.Y., et al. (2016) Validation of the Global Land Data Assimilation System Based on Measurements of Soil Temperature Profiles. Agricultural \& Forest Meteorology, 218, 288-297. https://doi.org/10.1016/j.agrformet.2016.01.003

[18] Fu, X.L. and Wang, B. (2014) Reliability Evaluation of Soil Moisture and Land Surface Temperature Simulated by Global Land Data Assimilation System (GLDAS) Using AMSR-E Data. Proceedings of SPIE-The International Society for Optical Engineering, 9265, 92650O1-5. 
[19] Pan, H.L. and Mahrt, L. (1987) Interaction between Soil Hydrology and Boundary-Layer Development. Boundary-Layer Meteorology, 38, 185-202. https://doi.org/10.1007/BF00121563

[20] Chen, F. and Dudhia, J. (2001) Coupling an Advanced Land Surface-Hydrology Model with the Penn State-NCAR MM5 Modeling System. Part II: Preliminary Model Validation. Monthly Weather Review, 129, 587-604. https://doi.org/10.1175/1520-0493(2001)129<0587:CAALSH>2.0.CO;2

[21] Ek, M.B., Mitchell, K.E., Lin, Y., et al. (2003) Implementation of Noah Land Surface Model Advances in the National Centers for Environmental Prediction Operational Mesoscale Eta Model. Journal of Geophysical Research, 108, 8851. https://doi.org/10.1029/2002JD003296

[22] Guo, W.Y. (2008) Trend Analysis of Ecological Footprint Time Series Based on Mann-Kendall Test. Yunnan Geographic Environment Research, No. 5, 33-37.

[23] Zhou, Y., Gao, X.Q., Zhang, K., Li, Y.J. and Yang, L.W. (2020) Spatiotemporal Variations in $3.2 \mathrm{~m}$ Soil Temperature in China during 1980-2017. Climate Dynamics, 54, 1233-1244. https://doi.org/10.1007/s00382-019-05055-x

[24] Chu, S. and Chen, L. (2011) Evaluation of Energy Saving and Emission Reduction in Anhui Province Based on Coefficient of Variation Method. China Population, Resources and Environment, No. 8, 512-516.

[25] Nearing, M.A., Govers, G. and Norton, L.D. (1999) Variability in Soil Erosion Data from Replicated Plots. Soil Science Society of America Journal, 63, 1829-1835. https://doi.org/10.2136/sssaj1999.6361829x

[26] Dong, F., Xu, X.H., et al. (2014) Analysis of Regional Differences of Carbon Emission in China. Resources and Environment in the Yangtze Basin, 11, 1526-1533.

[27] Wei, Z.F., Huang, Q.Y. and Zhang, R. (2019) Dynamics of Vegetation Coverage and Response to Climate Change in China-South Asia-Southeast Asia during 1982-2013. Applied Ecology and Environmental Research, 17, 2865-2879. https://doi.org/10.15666/aeer/1702_28652879

[28] Sun, Y.L., Shan, M., Pei, X.-R., Zhang, X.K. and Yang, Y.L. (2020) Assessment of the Impacts of Climate Change and Human Activities on Vegetation Cover Change in the Haihe River Basin, China. Physics and Chemistry of the Earth, Parts $A / B / C$, 115, Article ID: 102834. https://doi.org/10.1016/j.pce.2019.102834

[29] Li, Z. and Pan, J.H. (2018) Spatiotemporal Changes in Vegetation Net Primary Productivity in the Arid Region of Northwest China, 2001 to 2012. Frontiers of Earth Science, 12, 108-124. https://doi.org/10.1007/s11707-017-0621-8

\section{Abbreviations}

The following abbreviations are used in this manuscript:

$\begin{array}{ll}\text { CV: } & \text { Coefficient of Variation } \\ \text { GLDAS: } & \text { Global Land Data Assimilation System } \\ \text { CLM3.5: } & \text { Community Land Model } \\ \text { IBIS: } & \text { Integrated Biosphere Simulator }\end{array}$

